\title{
Sonoelastographic Findings in Clubfeet
}

\author{
Andrei Corbu (iD)' \\ Dan Ionut Cosma ${ }^{2}$ \\ Dana Elena Vasilescu ${ }^{3}$ \\ Dan Vasilescu ${ }^{4}$ \\ Stefan Cristea'
}

'University of Medicine and Pharmacy Carol Davila Bucharest, Romania, Department of Orthopaedics and Traumatology, Bucharest, Romania; ${ }^{2}$ Clinical Rehabilitation Hospital Cluj-Napoca, Department of Orthopaedics and Traumatology, Cluj-Napoca, Cluj, Romania; ${ }^{3}$ University of Medicine and Pharmacy luliu Hatieganu, Cluj-Napoca, Romania; Department of OrthopaedicsTraumatology and Paediatric Orthopaedics, Cluj-Napoca, Cluj, Romania; ${ }^{4}$ Clinical Emergency Hospital Cluj-Napoca, Department of Radiology and Imaging, Cluj-Napoca, Cluj, Romania
Correspondence: Dan Vasilescu

Clinical Emergency Hospital Cluj-Napoca, Department of Radiology and Imaging,

Clinicilor 3-5, Cluj-Napoca, Cluj, Romania

$\mathrm{Tel}+40264592771$

Email danvasi76@yahoo.com
Purpose: One of the main features of congenital idiopathic clubfoot is the increased stiffness of soft tissues. With the growing popularity and availability of sonoelastography as a method to assess the stiffness of different tissues, we considered applying it to congenital clubfeet in order to to determine whether sonoelastography can be a useful imaging method for the evaluation of clubfeet, to assess whether there are any differences in stiffness of specific tendons between clubfeet and normal contralateral feet and to observe which treatment methods have an impact on the aspect of these structures on the elastograms. Patients and Methods: A case-control study was performed involving 10 adolescent patients with unilateral idiopathic congenital clubfeet who were treated either with the Ponseti method or surgically with posteromedial release (PMR) during early infancy. Using compression sonoelastography, we obtained semi-quantitative data expressed as fat to tendon ratios in treated clubfeet and normal contralateral feet. The tendons of the following muscles were examined: tibialis anterior, tibialis posterior, flexor hallucis longus, peroneus longus and Achilles tendon at three levels (calcaneal insertion, lengthened zone and musculotendinous junction).

Results: The only statistically significant difference in the strain ratio $(p=0.023)$ between clubfeet and normal feet was at the level of the calcaneal insertion of the Achilles tendon, which was stiffer in clubfeet. Although other differences were not statistically significant, they may reflect some of the pathological modifications of clubfeet.

Conclusion: Overall, sonoelastography may be a useful examination tool in the quantitative and qualitative assessment of soft tissue stiffness in clubfeet, but further research is necessary.

Keywords: soft tissue elasticity, stiffness, tendons, clubfoot, ultrasound, elastography, Achilles tendon

\section{Introduction}

Congenital clubfoot is a common malformation with a reported incidence of 1 in 1000 live births. ${ }^{1}$ Clubfeet are characterized by the clinical presence of four deformities: cavus, adductus, varus and equinus. These deformities are the result of the underlying pathology, which is present mostly in the soft tissues. It has been shown that there is increased re-tractile fibrosis of the muscles, tendons and surrounding soft tissues localized distal to the knee joint in patients with clubfeet, which are accompanied by dysplastic modifications of bones and disturbance of the normal osteo-articular alignment. ${ }^{2,3}$ To achieve a plantigrade and functional foot, these contractures may be addressed either by performing surgery or by conducting serial manipulations and immobilizations of the clubfoot. Depending on the extensiveness of the procedure, surgical treatment can include plantar release (PL), posteromedial release (PMR) and complete subtalar release (CSTR). Regardless 
of the technique employed, the primary focus is on elongating the contracted soft tissues (muscles, tendons, ligaments, joint capsules) and restoring the normal anatomical relationships between the foot bones. The principle of conservative treatment is based upon the viscoelastic properties of tendons and ligaments, which, when immobilized in a lengthened position, undergo adaptive changes and become less stiff. ${ }^{4}$

The gold standard of treatment is the Ponseti method due to its capacity to achieve correction rates of up to $100 \%{ }^{5,6}$ Nevertheless, surgical treatment is still reserved for feet that remain incompletely corrected and in some cases of relapse. Despite the high initial correction rates, clubfeet are characterised by an increased tendency toward recurrence, which can reach a rate of $56 \%$ in some published reports, rendering a maintenance phase necessary. ${ }^{7,8}$ Relapse can be explained by an excessive collagen synthesis leading to the development of retracting fibrosis in the structures which are innervated by the posterior tibial nerve. ${ }^{9}$ Foot abduction orthoses (FAOs) are used for the prevention of relapses because, by maintaining the foot in external rotation and slight dorsiflexion, the stiff medial and posterior structures are constantly stretched. In general, evaluation of clubfeet is performed clinically and, when considered necessary, with the use of X-rays. Other imaging methods, such as computed tomography (CT), magnetic resonance imaging (MRI) and conventional ultrasound have been employed to study the morphological characteristics of foot bones and their alignment, but they have been mostly utilized for research purposes. As clubfoot represents a condition characterized by stiffness and sonoelastography has emerged as a noninvasive technique of tissue elasticity assessment, we consider that it could be useful in the evaluation of this pathology. This ultrasonographic imaging method assesses tissue stiffness, which reflects underlying structural pathological modifications, and has already been used in breast, liver and musculoskeletal pathology. The main techniques of elastography are represented by compression elastography or real-time elastography (RTE), shear wave elas-tography (SWE) and transient elastography. Compression elastography has become in-creasingly used for evaluating the elasticity of musculoskeletal structures, such as ligaments, tendons and muscles. ${ }^{10,11}$ This method involves applying uniform compression forces to the region of interest (ROI) and measuring the strains, which represent the degree of deformation of tissues and are determined by calculating the displacement between two points. The compression force and the subsequently induced deformation should be within certain limits, which can usually be monitored by an indicator on the screen in order to obtain good quality elastograms. Tissues that exhibit more deformation are softer and tissues that deform less are stiffer. Elastograms can be interpreted semiquantitavely or qualitatively.

The purpose of this study was to determine whether sonoelastography can be a useful imaging method for the evaluation of clubfeet, to assess whether there are any differences in stiffness of specific tendons between clubfeet and normal contralateral feet and to observe which treatment methods have an impact on the aspect of these structures on the elastograms.

\section{Patients and Methods}

\section{Study Design}

This analytical, case-control study was conducted in the Clinical Rehabilitation Hospital Cluj-Napoca from November 2019 to November 2020 in accordance with the Declaration of Helsinki after obtaining approval from the local institutional ethics committee (approval no. 6/2019). We identified the clinical records of patients diagnosed with idiopathic congenital unilateral clubfoot who were treated at our clinic. Invitations to participate in the study were mailed to their families. Prior to participation, informed consent forms were signed by the legal guardians of the participants in the study. We included only patients with idiopathic unilateral clubfoot who were older than 10 years of age (due to cooperation related concerns) with plantigrade, normal looking (defined as absence of cavus, varus, adductus and equinus deformities) and functional (defined as ability to toe-walk, heel-walk, absence of limping and dynamic supination) clubfeet at clinical examination. Patients with arthrogrypotic, neuromuscular clubfeet were excluded. As joint hyperlaxity can be a protective factor against relapse in clubfeet and we considered that it might influence the stiffness of tendons on elastograms, we also decided to exclude patients who exhibited any sign of hyperlaxity from the study. ${ }^{12}$ Further, we opted to exclude patients who had report any type of foot or ankle pain in the three months prior to the evaluation as this could have been correlated with tendinopathy, which might influence stiffness measurements. None of the patients included in this study practised performance sports, which can also influence results as athletes can have stiffer tendons than the general population. ${ }^{13}$ Ten patients who agreed to participate were finally included in the study, six of whom were treated using the Ponseti method and four of whom were treated surgically using the PMR technique described 
by Turco, followed by immobilisation in a long leg plaster cast for eight weeks. ${ }^{14,15}$ A percutaneous Achilles tendon tenotomy was performed in all patients treated with the Ponseti method after achieving correction of cavus, adductus and varus deformities. Following correction, both groups of patients were prescribed FAOs; patients treated using the Ponseti method were instructed to wear them according to the Ponseti protocol - 23 hours/day in the first three months and 16 hours/day afterwards for the following three years. After cast removal, surgically treated patients were prescribed customised FAOs and instructed to wear them at nighttime and naptimes for the following two years.

\section{Imaging Acquisitions}

Clubfeet and normal contralateral feet were assessed using a Hitachi Noblus (Hitachi Aloka Medical Corporation, Tokyo, Japan) ultrasound system with a 5- to $13-\mathrm{MHz}$ linear transducer in all patients. Imaging acquisition was performed using the RTE function of the device by the same examiner (D. V.), who has more than 10 years of experience in both conventional ultrasound and RTE. The compression force and subsequently induced deformation were within limits as displayed on the screen indicator. Our study protocol included RTE examination of the following tendons: tibialis anterior (TA), tibialis posterior (TP), peroneus longus (PL), flexor hallucis longus (FHL) and Achilles tendon (AT). The latter was assessed at three levels: the calcaneal insertion (AT-CI), lengthened region (AT-L) and myotendinous junction (AT-MT). To avoid uneven tendon tensioning with different degrees of plantar flexion, all feet were examined while remaining aligned with the calf and positioned in $30^{\circ}$ of plantar flexion, with the angle being measured using a goniometer. The tibialis anterior (Figure 1), tibialis posterior (Figure 2) and peroneus longus tendons were assessed with the patient supine, while the Achilles tendon (Figures 3-5) and the flexor hallucis longus tendon (Figure 6) were evaluated with the patient prone having the feet hanging off the table Except for the PL, all tendons were assessed using the longitudinal section. Before performing the sonoelastographic assessment, the ROI of each tendon was identified by B-mode ultrasound. For each tendon, measurements were initially performed in clubfeet. After calculating the distance of the evaluated ROI from the adjacent bony landmarks, the ROI was evaluated at the same level in the contralateral tendon.

The TA tendon was examined just above the extensor retinaculum on the lateral side the distal third of the tibia, the TP tendon was assessed at the level of the medial malleolus, and the FHL tendon on the plantar aspect of the foot, in the area where it becomes visible after traversing between the two heads of the flexor hallucis brevis muscle. The longitudinal sections of each of the 3 ROI of the Achilles tendon were obtained with the patient prone. The lengthened zone of the Achilles tendon was recognizable by the relatively relative difference in homogeneity in comparison to the rest of the tendon. In the case of the PL tendon (Figure 7), it was not possible to obtain an adequate longitudinal elastographical section in the

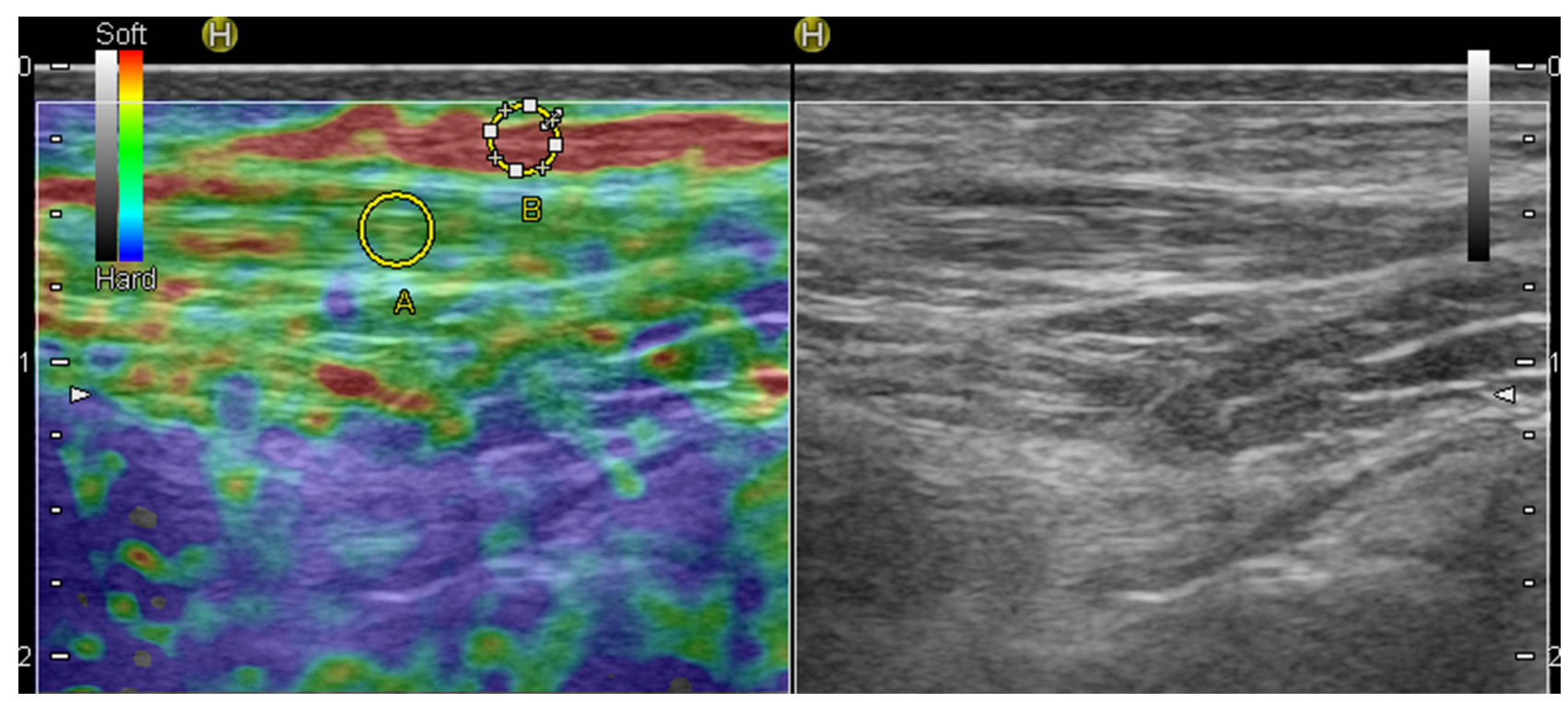

Figure I Sonoelastogram (left side) and B-mode ultrasound image (right side) of the TA tendon. $B=$ subcutaneous area of fat taken into consideration for measuring the fat strain, $A=$ area of the tendon which was taken into consideration for measuring the tendon strain. In this study, the fat tendon ratio = B/A. 


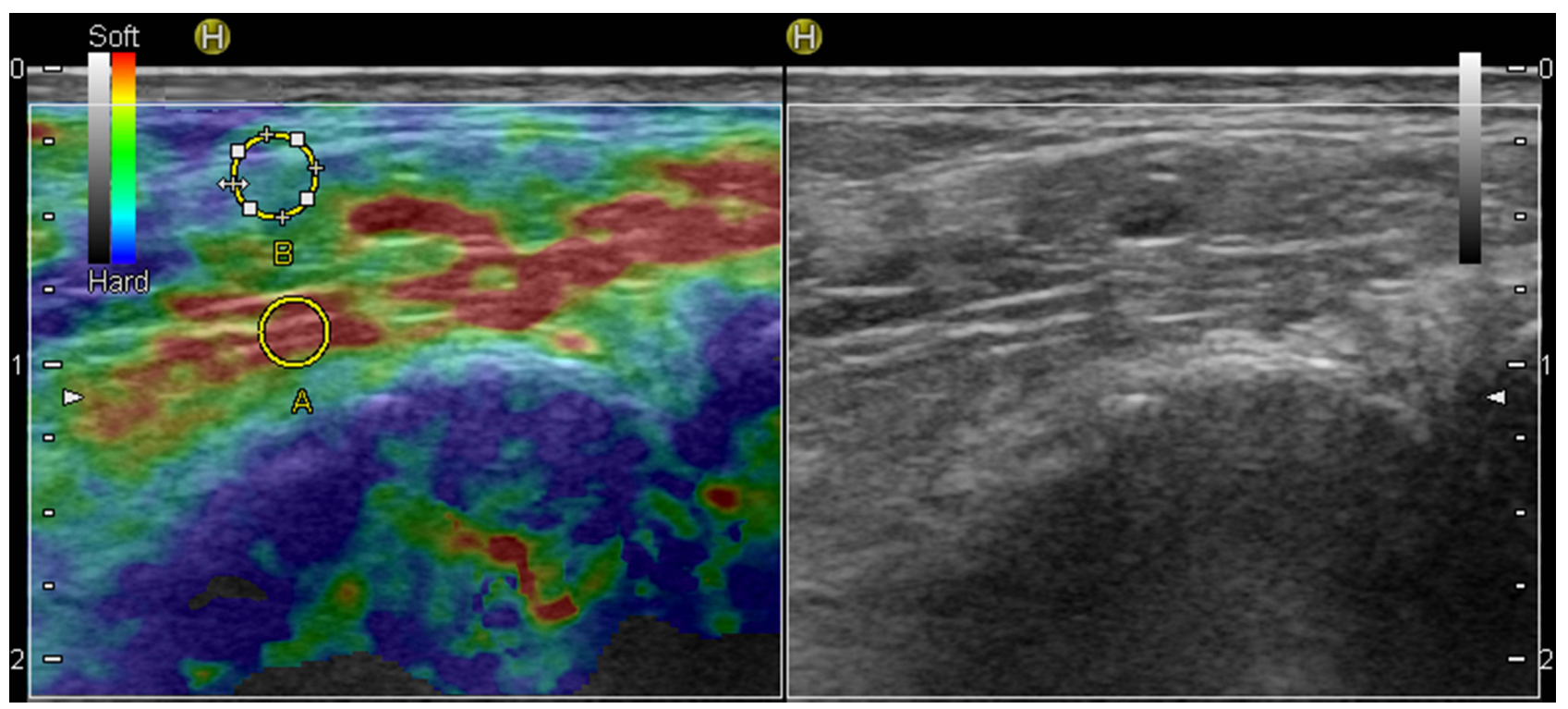

Figure 2 Sonoelastogram (left side) and B-mode ultrasound image (right side) of the TP tendon.

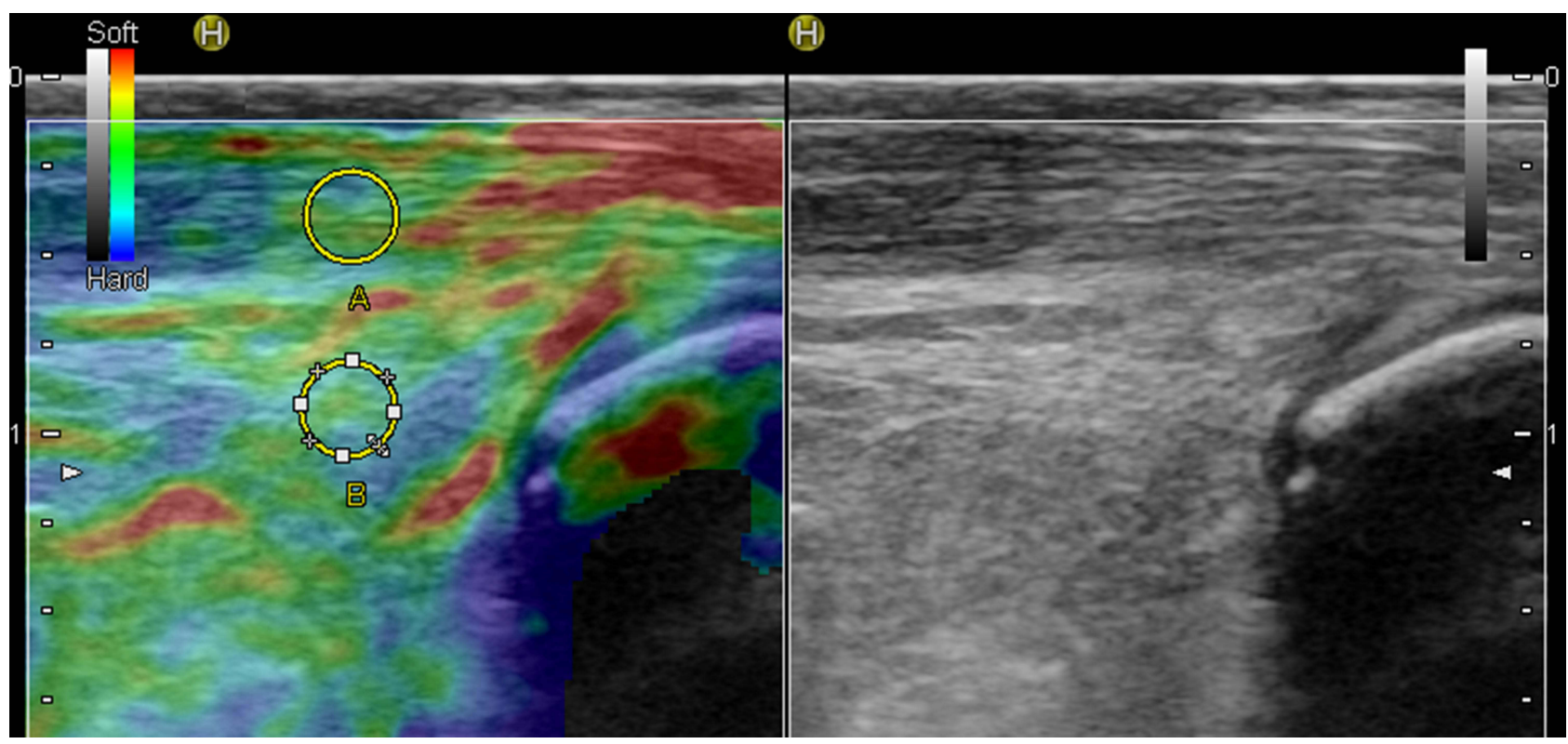

Figure 3 Sonoelastogram (left side of the images) of the Achilles tendon insertion and corresponding B-mode ultrasound images (right side of the images) of the same area. In this ROI, the Kager fat pad was employed for the calculation of fat strain and the SR. B = fat tissue taken into consideration for the calculation of fat strain, $A=$ area of tissue taken into consideration for the calculation of tendon strain.

retromalleolar fibular groove in two feet, so we obtained transverse elastographical sections instead in all patients.

\section{Semi-Quantitative and Qualitative Data Analysis}

To be able to compare the tendons in clubfeet and contralateral feet, RTE images were assessed using quantitative measurement of the strains produced in the examined tendons and in the adipose tissue adjacent to them. The measured differences of the strains were expressed as the strain ratio (SR). SR values for each of the seven evaluated tendinous regions were obtained by dividing the adipose strain (B) by the tendon strain (A). In most patients, the local anatomy allowed us to use the subcutaneous fat strain to calculate the SR. At the level of the calcaneal insertion of the Achilles tendon, however, we could not achieve good-quality elastograms and measurements using the subcutaneous fat strain in some patients, so we used 


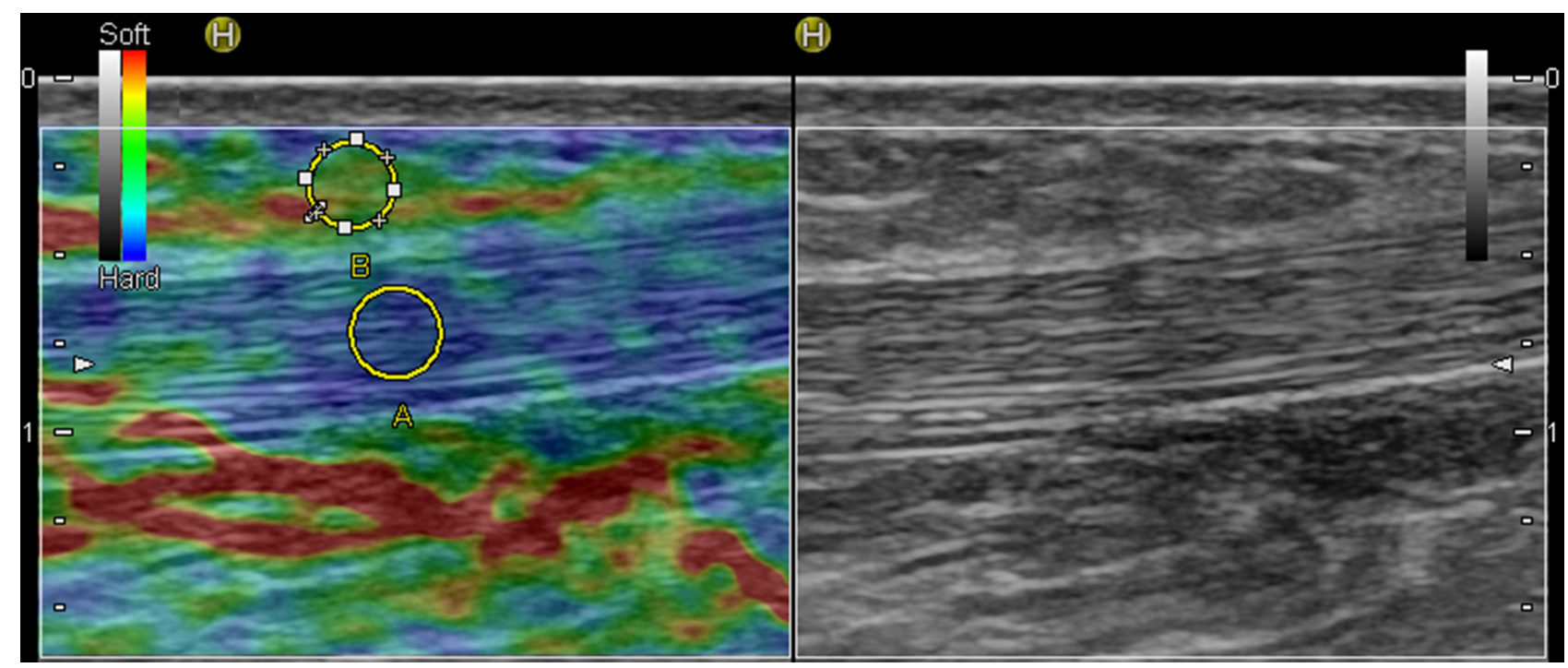

Figure 4 Sonoelastogram (left side of the images) of the lengthened region of the AT and corresponding B-mode ultrasound images (right side of the images) of the same area.

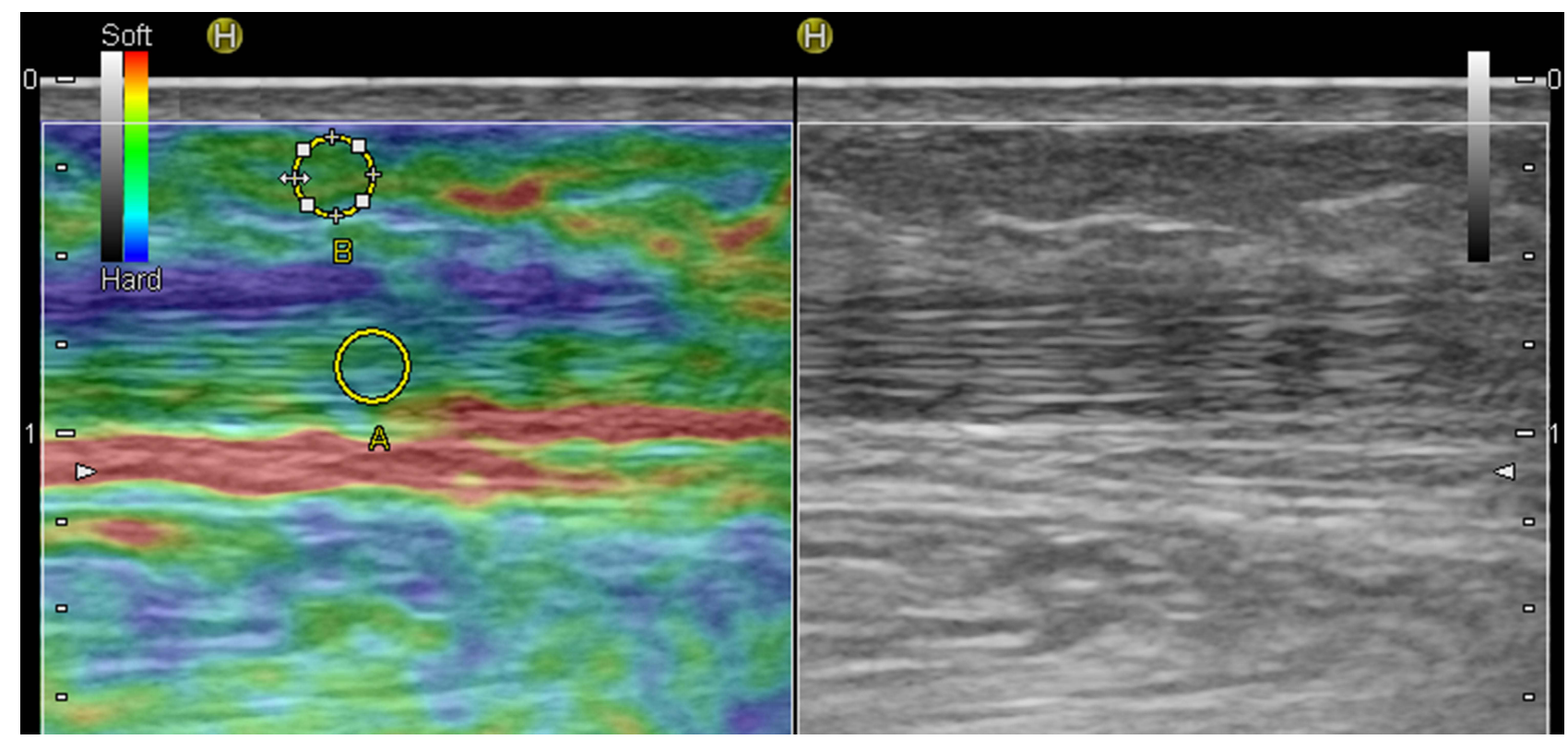

Figure 5 Sonoelastogram (left side of the images) of the musculotendinous junction of the AT Achilles tendon and corresponding B-mode ultrasound images (right side of the images) of the same area.

the pre-Achilles fat pad strain to calculate the SR in all patients instead. An increased strain value of a certain tissue implies a softer structure, while a decreased strain value is characteristic of a stiffer structure. A smaller value of the SR means that the tendon is softer and more compressible in relation to fat tissue, whereas a higher value of SR means that the tendon is stiffer and less compressible in relation to the fat tissue. Qualitative tendon assessments were also possible as the ultrasound system allows colour codification of stiffness. On elastograms, blue indicates a stiff structure, red indicates a soft structure and green indicates a structure of intermediate stiffness. We used these parameters only as a guide to appreciate the quality of elastograms during compression, prior to choosing the semi-quantitative measurements.

\section{Statistical Analysis}

Statistical analysis was performed using the SPSS Statistics for Windows, version 26.0 software program (IBM Corporation, Armonk, NY, USA). Data were 


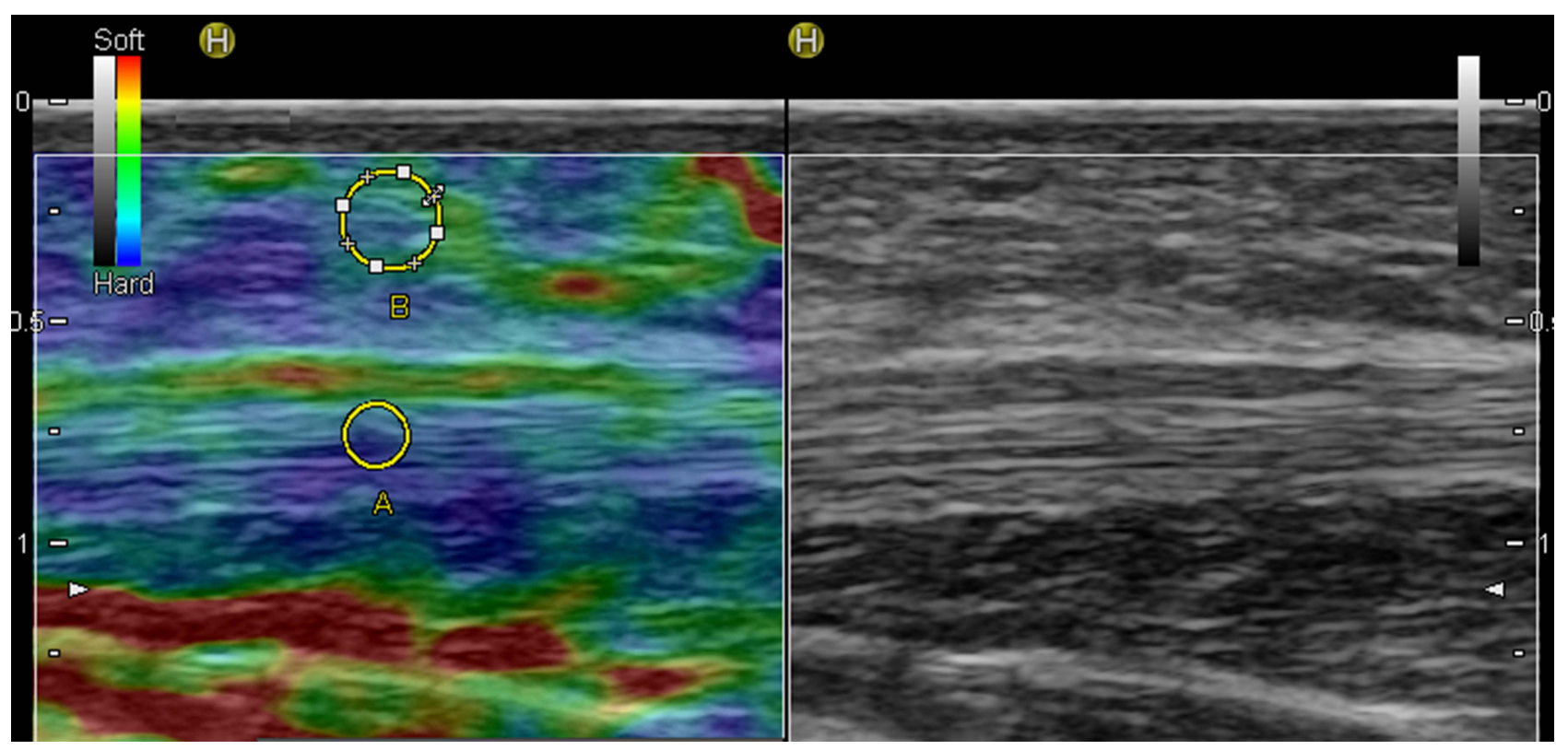

Figure 6 Sonoelastogram (left side of the images) and corresponding B-mode ultrasound images (right side of the images) of the FHL tendon.

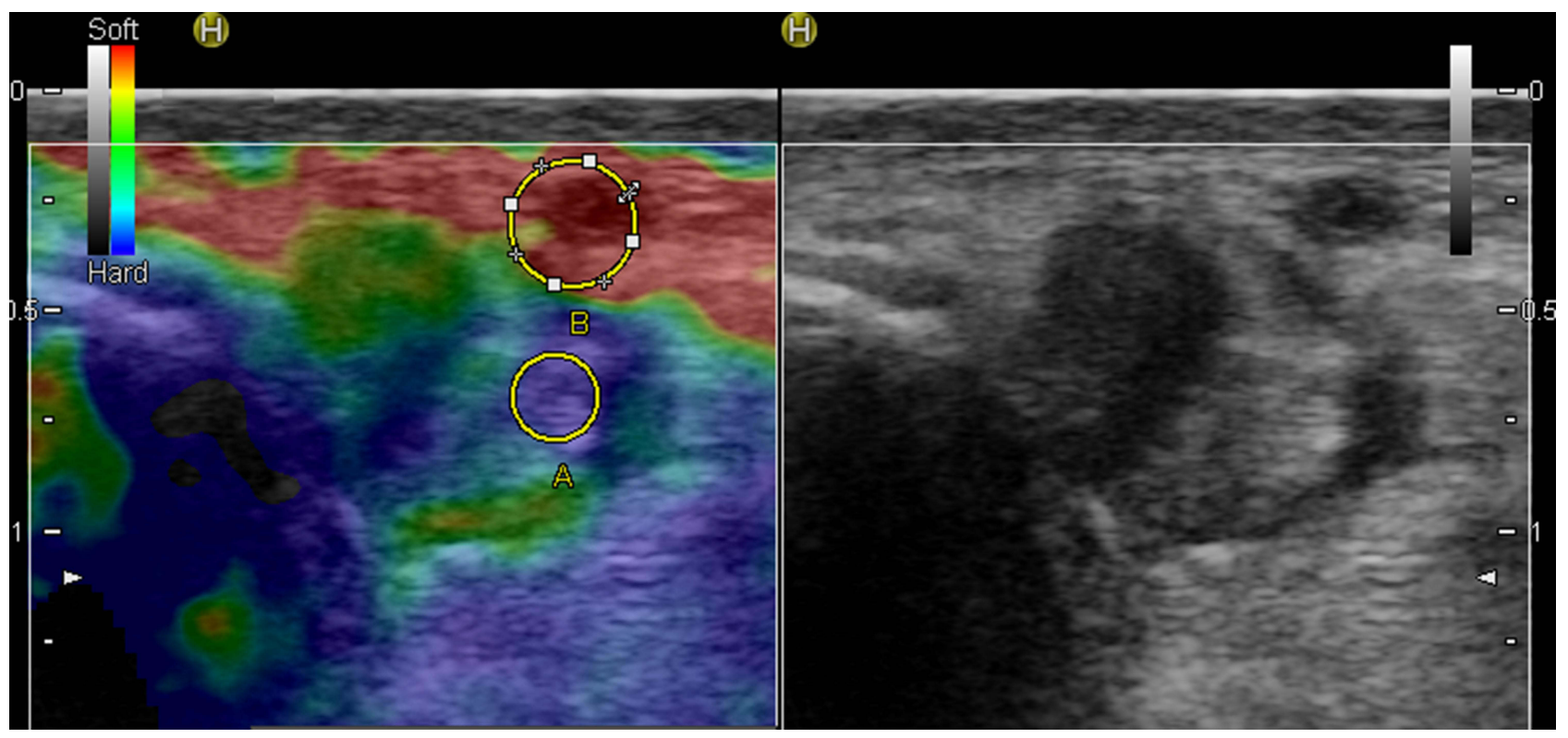

Figure 7 Sonoelastogram (left side of the images) and corresponding B-mode ultrasound images (right side of the images) of the PL tendon. In this ROI, transversal sections were acquired in all patients.

checked for normality of distribution using the ShapiroWilk test and were expressed with medians and interquartile range (IQR). Comparisons between groups were performed using the Mann-Whitney $U$-test. A p value of less than 0.05 was considered to be statistically significant.

\section{Results}

Ten patients with unilateral clubfoot were finally included in this study. The Ponseti group consisted of six patients who were treated conservatively using the Ponseti method at a mean age of $2.66 \pm 1.63$ months. The remaining four patients with clubfeet, which was corrected surgically with PMR at a mean age of $10.5 \pm 1.91$ months, formed the surgical group. RTE analysis was conducted at a mean age of $154 \pm 22.71$ months in the Ponseti group and $176 \pm 21$ months in the surgical group. The overall stiffness as reflected by the sum of median SR values was greater in clubfeet (12.64) as compared with in normal feet (9.56). Excluding the PL and FHL 
Table I SR Values for Each Tendon in Clubfeet and Contralateral Normal Feet

\begin{tabular}{|c|c|c|c|}
\hline Tendon & $\begin{array}{c}\text { Normal foot } \\
\text { (Median, IQR) }\end{array}$ & $\begin{array}{c}\text { Clubfoot } \\
\text { (Median, IQR) }\end{array}$ & $\begin{array}{l}\text { Statistical } \\
\text { Significance }\end{array}$ \\
\hline TA & $1.86(0.91-3.05)$ & $2.06(1.81-3.33)$ & $p=0.43$ \\
\hline TP & $0.7(0.53-2.4)$ & $1.95(1.07-5)$ & $P=0.123$ \\
\hline $\mathrm{FHL}$ & 0.91 (0.75-I.42) & $0.66(0.52-1.04)$ & $P=0.089$ \\
\hline PL & $2.59(1.39-3.55)$ & $2.28(0.64-8.24)$ & $P=0.912$ \\
\hline AT-Cl & $0.72(0.46-1.17)$ & $\mathrm{I} .5(1.02-3.96)$ & $P=0.023$ \\
\hline AT-L & $1.53(0.57-3.2)$ & $2.05(1.31-3.09)$ & $P=0.315$ \\
\hline AT-MT & $1.25(0.9-2,44)$ & $2.14(0.84-6.34)$ & $P=0.48 I$ \\
\hline
\end{tabular}

Abbreviation: IQR, interquartile range.

tendons, the rest of the tendons were characterised by greater global SR in relation to the corresponding tendons of normal feet (Table 1). The difference was statistically significant only for the Achilles tendon at the level of its calcaneal insertion $(\mathrm{p}=0.023)$.

In comparison with normal contralateral feet, clubfeet treated conservatively showed increased median SR values in the TA, TP and PL tendons and AT tendon at all three levels (Table 2). Lower median SR values were observed in the FHL tendon. There was not any statistical significance regarding the SR values of tendons between clubfeet and normal feet in the Ponseti group.

Patients included in the surgical group also demonstrated higher median SR values for the TA, TP and Achilles tendon at the calcaneal insertion. The lengthened zone and the myotendinous junction of the AT were softer and presented lower median SR values in comparison with normal feet (Table 3).

A comparative analysis of clubfeet according to the type of treatment received revealed higher SR values for TA, TP, FHL and PL tendons in conservatively treated

Table 2 SR Values for Each Tendon in Clubfeet and Contralateral Normal Feet of Patients Treated Using the Ponseti Method

\begin{tabular}{|l|c|c|c|}
\hline Tendon & $\begin{array}{c}\text { Normal Foot } \\
\text { (Median, IQR) }\end{array}$ & $\begin{array}{c}\text { Ponseti } \\
\text { Clubfeet } \\
\text { (Median, IQR) }\end{array}$ & $\begin{array}{c}\text { Statistical } \\
\text { Significance }\end{array}$ \\
\hline TA & I.86(I.03-4.6) & $2.17(1.96-3.48)$ & $\mathrm{P}=0.394$ \\
TP & $0.74(0.64-3.74)$ & $2.58(0.86-10,15)$ & $\mathrm{P}=0.310$ \\
FHL & $0.86(0.71-1.24)$ & $0.7(0.52-1,99)$ & $\mathrm{P}=0.485$ \\
PL & $2.94(1.8-52.27)$ & $3.67(1.22-56,69)$ & $\mathrm{P}=1$ \\
AT-Cl & $0.65(0.26-1.17)$ & $1.21(0.63-2,57)$ & $\mathrm{P}=0.180$ \\
AT-L & $0.9(0.37-2.08)$ & $1.77(1.08-3.09)$ & $\mathrm{P}=0.132$ \\
AT-MT & $1.18(0.79-1.55)$ & $1.85(0.82-6,34)$ & $\mathrm{P}=0.394$ \\
\hline
\end{tabular}

Abbreviation: IQR, interquartile range.
Table 3 SR Values for Each Tendon in Clubfeet and Contralateral Normal Feet of Patients Treated Surgically

\begin{tabular}{|l|c|c|c|}
\hline Tendon & $\begin{array}{c}\text { Normal Foot } \\
\text { (Median, IQR) }\end{array}$ & $\begin{array}{c}\text { Surgically } \\
\text { Treated } \\
\text { Clubfeet } \\
\text { (Median, IQR) }\end{array}$ & $\begin{array}{c}\text { Statistical } \\
\text { Significance }\end{array}$ \\
\hline TA & $1.54(0.5-2.48)$ & $1.76(1.07-3,67)$ & $\mathrm{P}=\mathrm{I}$ \\
TP & $0.6(0.43-2.12)$ & $1.95(1.19-2,3 \mathrm{I})$ & $\mathrm{P}=0.343$ \\
FHL & $I .1(0.82-1.9)$ & $0.62(0.45-0.95)$ & $\mathrm{P}=0.114$ \\
PL & $1.84(0.93-3.1)$ & $1.56(0.33-9.73)$ & $\mathrm{P}=\mathrm{I}$ \\
AT-CI & $0.86(0.54-1.29)$ & $2.76(1.33-7.5 \mathrm{I})$ & $\mathrm{P}=0.057$ \\
AT-L & $3.83(1.24-7.45)$ & $2.07(1.62-6.84)$ & $\mathrm{P}=\mathrm{I}$ \\
AT-MT & $2.56(1.07-3.5 \mathrm{I})$ & $2.47(0.86-33.15)$ & $\mathrm{P}=0.886$ \\
\hline
\end{tabular}

Abbreviation: IQR, interquartile range.

Table 4 SR Values for Each Tendon in Clubfeet of Patients Treated Surgically and Using the Ponseti Method

\begin{tabular}{|l|c|c|c|}
\hline Tendon & $\begin{array}{c}\text { Surgically } \\
\text { Treated } \\
\text { Clubfeet } \\
\text { (Median, IQR) }\end{array}$ & $\begin{array}{c}\text { Ponseti Clubfeet } \\
\text { (Median, IQR) }\end{array}$ & $\begin{array}{c}\text { Statistical } \\
\text { Significance }\end{array}$ \\
\hline TA & $1.76(1.07-3,67)$ & $2.17(1.96-3.48)$ & $P=0.352$ \\
TP & $1.95(1.19-2,3 I)$ & $2.58(0.86-10,15)$ & $P=0.762$ \\
FHL & $0.62(0.45-0.95)$ & $0.7(0.52-1,99)$ & $P=0.6 I$ \\
PL & $1.56(0.33-9.73)$ & $3.67(1.22-56,69)$ & $P=0.6 I$ \\
AT-CI & $2.76(1.33-7.5 I)$ & $1.21(0.63-2,57)$ & $P=0.257$ \\
AT-L & $2.07(1.62-6.84)$ & $1.77(1.08-3.09)$ & $P=0.476$ \\
AT-MT & $2.47(0.86-33.15)$ & $1.85(0.82-6,34)$ & $P=0.762$ \\
\hline
\end{tabular}

Abbreviation: IQR, interquartile range.

clubfeet (Table 4). AT presented higher values in surgically treated clubfeet in all examined regions; however, there was not any statistically significant difference in this regard between the two groups.

\section{Discussion}

Congenital clubfoot is a complex three-dimensional malformation and, besides its typical four deviations, stiffness represents a characteristic constant finding. Taking into consideration the typical rigid medial and plantar flexion deviation of the foot and ankle, it is appropriate to consider that the posteromedial soft tissues are stiffer than the lateral and dorsal soft tissues. Depending on the severity, these capsular, ligamentous and tendinous structures become involved to various degrees and their stiffness might differ from one clubfoot to another. Importantly, the pathological modifications described in various research studies are not constantly present. Given the clinical evolution of clubfeet and the characteristic 
increased tendency to recur until the age of four or five years, the theory of retracting, probably genetically induced, fibrosis of soft tissues and muscle-tendon units formulated by Ippolito seems plausible. ${ }^{3}$

The effects on soft tissue elasticity following correction using the Ponseti method or surgical release should also be considered. Employing serial manipulation and immobilization sessions, the Ponseti method exploits the viscoelastic properties of tendons, which makes them more deformable at low strain rates but less deformable at high strain rates. ${ }^{16}$ Thus, by producing a constant strain in the tendons on the posteromedial aspect of the foot and ankle, a deformation and lengthening process is gradually induced. This effect is known as stress relaxation and Kadhum et al consider that it is controlled by two events taking place in the soft tissues: rearrangement of the tendon microstructure, characterized by a proteoglycan-controlled process of reorganisation, and interfiber and interfibrillar sliding of collagen, which also appears to promote a kind of secondary subtle tissue growth, further enhancing the stress relaxation. ${ }^{17}$ With surgical treatment, represented in our case by PMR, the TP and Achilles tendons were lengthened with a Z-plasty technique, and the necessary posteromedial capsulotomies and ligamentous releases were performed until correction was obtained. Correction was maintained using a Kirschner wire inserted through the talonavicular joint and removed at six weeks postoperatively. All patients were immobilised in a long leg plaster cast for eight weeks. It is a known fact that, irrespective of the surgical technique (eg, PMR, complete subtalar release), healing occurs through a scarring process, resulting in fibrous tissue encasing the posteromedial aspect of the foot and ankle. Despite the good short-term results after surgery, recurrence and stiffness in the foot and ankle are more frequent after surgical treatment as the resulting connective scar tissue presents an increased tendency to retract. ${ }^{18,19}$ Thus, there is a fundamental difference concerning the structural effects of the two treatment methods. Surgical treatment addresses the posteromedial contractures by releasing or lengthening them, without any remodelling effect on an ultrastructural level, probably without any significant changes related to the retracting soft tissue fibrosis. With skeletal growth, the surgically lengthened tendons tend to become shortened, scarred and more adherent to adjacent tissues, and an overlapping retractile effect produced by the postsurgical connective tissue scar formation might be added. From this point of view, we would expect to find increased stiffness of the posteromedial tendons in surgically treated clubfeet in comparison with among patients treated using the Ponseti method.

The results of our observational study showed that the overall stiffness was increased in clubfeet relative to in normal feet. When comparing the measurements between different groups of the study population (ie, normal feet vs clubfeet, surgically treated feet vs normal contralateral feet, Ponseti-treated clubfeet vs normal contralateral feet, surgically treated clubfeet vs Ponseti-treated clubfeet), the differences between each tendon were significant, with the exception of the calcaneal insertion of the Achilles tendon, which was stiffer in clubfeet than in normal contralateral feet. Multiple reasons may account for the lack of statistically significant differences. First, the study population was small. Therefore, even though $\mathrm{p}$ values were greater than 0.05 , we do not know whether differences exist or not. ${ }^{20,21}$ Second, pathological anatomical modifications in tendons are variable and inconstantly described in the literature; thus, stiffness values might be influenced by the severity of clubfeet at presentation. Third, by the time of follow-up, it can be assumed that initial treatment reduced either partially or completely the stiffness of clubfeet. It has also been demonstrated that a four-week static stretching programme reduces passive stiffness of gastrocnemius muscle-tendon units, so bracing can influence the final measurements. ${ }^{22}$ In addition, the contractility of ligaments and tendons that are primarily involved might decrease in time so that, once a static equilibrium is reached, it is probable that the deformity will not recur. ${ }^{23}$ Lastly, as a response to physical activity, human tendons suffer adaptive changes, such as increases in collagen synthesis, which can asymmetrically increase tendon stiffness, depending upon the dominance of the limb. ${ }^{24,25}$

In clubfeet, the peroneal tendons are stretched and lengthened due to the initial deviation. ${ }^{26,27}$ With treatment, as the foot is brought in the corrected position, they may become laxer than in normal feet. Functionally, the peroneal muscles appear weaker initially and their strength improves after correction in some patients. ${ }^{26}$ Poor activity in the evertor muscles has been demonstrated in both idiopathic and non-idiopathic clubfeet after conservative or surgical treatment and was associated with recurrence of the deformity. ${ }^{28-30}$ Although we have not recorded any experimental data (there was no statistical statistically significant difference in the peroneal tendons of clubfeet in comparison with normal feet; overall, SR suggested 
slightly stiffer peroneal tendons existed in clubfeet) to verify this theory, we consider that both muscle weakness (which can reduce tension in the tendons) and an increased tendon length may result in a softer aspect on the elastograms. We found the overall SR of the peroneus longus to be minimally reduced in clubfeet, but we do not have a plausible explanation for its variation according to the initial treatment: the PL tendon was stiffer in Ponsetitreated clubfeet in comparison with in surgically treated clubfeet and normal contralateral feet, while surgically treated clubfeet presented softer SR values as compared with contralateral normal feet.

At the posteromedial aspect of the foot and ankle, the tibialis posterior tendon has been considered one of the most important anatomic elements involved in the clubfoot deformity. Fried reported an important thickening of the tendon, having a hard, fibrotic structure on the medial side of the tarsus. ${ }^{31}$ Bensahel described the thickening of the tendon and of its sheath, considering such to be the primary deforming force in clubfeet. ${ }^{32}$ A histological study conducted by Ippolito also found increased connective tissue in the muscle belly, thickening of its sheaths and of the distal tendon. ${ }^{3}$ Taking into consideration these pathological structural modifications, it is logical to assume that the TP tendon would appear stiffer on elastograms. In our study population, the TP tendon was stiffer in clubfeet in comparison with in normal feet, irrespective of the treatment method (Tables 1-3).

Reports of structural alterations in the tibialis anterior tendon are scarce in the literature; more often, the tendon is described as being displaced medially, thus changing its acting direction. Nevertheless, Wicart et al describe the TA tendon as being shortened, displaced medially and having the consistency of a tense cord at the level of the medial malleolus. ${ }^{33}$ Turco described an abnormal insertion of the TA tendon, distal to the base of the first metatarsal, in some patients with resistant clubfoot and advocated its proximal reinsertion to decrease tension. ${ }^{15}$ Forefoot adduction and dynamic supination are some of the most frequent deformities of the foot after both surgical and conservative treatments and there is a consensus that they are the result of an overactive tibialis anterior tendon, whose pull is augmented in the presence of weaker peroneal muscles. ${ }^{34}$ These particularities might concur to produce a stiffer aspect on elastograms. Similar to the TP tendon, the TA tendon was stiffer in clubfeet in comparison with in normal feet, but the differences were minimal (Tables 1-3). Although not statistically significant, we cannot exclude that these differences in stiffness may be related to the persistence of stiffness in the TA and TP tendons in the long term. Macroscopical and histological descriptions of pathological modifications in the Achilles tendon have been well described and are consistent across most reports. In clubfeet, the tendon is much thicker; has a wider, sometimes more medial insertion in comparison to normal feet; and may receive fibrous tissue bands from the posteromedial ligaments in the ankle. ${ }^{2,34}$ Meanwhile, the triceps surae muscle is shortened; fibrotic; and contains a variable amount of intercellular connective tissue, which seems to decrease with growth. ${ }^{9}$ The fact that the tendon requires surgical lengthening in most patients is also an argument in favour of its increased stiffness. As indicated by the overall SR value, the AT in clubfeet presented with decreased elasticity; however, the difference was statistically significant only at the level of its calcaneal insertion: this region was stiffer in both the surgical and Ponseti groups in comparison with among normal contralateral feet, but the differences in elasticity for each group were not statistically significant. In the surgical group, the CI of the Achilles tendon was stiffer in comparison to patients treated with the Ponseti method, which could be linked to the development of stiffer connective scar tissue that forms after PMR secondary to posterior capsulotomy of the ankle or surgical injury of the pre-Achilles fat pad or AT paratenon.

Even though the lengthened area of the AT was generally stiffer in clubfeet in comparison to normal contralateral feet, its characteristics were different depending upon treatment. With respect to normal feet in each group, the AT-L area was softer in surgically treated patients, while in patients treated with the Ponseti method, it was stiffer. Most elastographical studies have described that the normal Achilles tendons have homogenous stiff patterns. ${ }^{35-38}$ During the proliferative stage of healing, the scar tissue contains more type III collagen instead of type I collagen and the fibers are structurally disorganized. ${ }^{39}$ Several elastographic studies have documented increased tendon stiffness during healing in surgically repaired Achilles tendons, which might be explained by the presence of fibrosis in the tendon and surrounding tissues. ${ }^{40-42}$ Starting with the reparative phase, the type and the total collagen content change, and type I collagen fibers reorganize longitudinally, increasing tendon strength and elasticity. ${ }^{43}$ Employing RTE, Busilachi et al observed that after surgery, treated Achilles tendons become progressively stiffer, with a tendency to 
reduce in 1 year, but without reaching "restitutio ad integrum". 42 This finding could partly explain the increased stiffness of the AT-L region in the Ponseti group. On the other hand, Zhang et al examined ruptured Achilles tendons treated with open surgery and demonstrated that functional outcomes are positively correlated with elasticity, thus lower elastic modulus values might predict poor mechanical properties, functional outcomes, and healing of repaired tendons. $^{40}$ Taking into consideration this finding, poor healing of the AT-L region in surgically treated clubfeet might be associated with a more disorganized structure and less remodeling potential, which could be reflected by lower elasticity modulus values. Interestingly, the overall SR in the AT-MT region was increased in comparison to normal feet, probably due to increased stiffness in clubfeet treated with the Ponseti method, as the differences between surgically treated clubfeet and normal contralateral feet were minimal. In this ROI, our initial assumption was that the MT junction of Ponseti treated clubfeet would be softer in comparison to the normal contralateral feet secondary to lengthening of the muscle-tendon units in response to the prolonged static stretch exerted by the FAO orthoses. $^{22}$

Although the FHL tendon is initially tight, we found that its retraction and stiffness after treatment is debatable. The differences in stiffness were minimal in our study group. McKay and Simons recommended performing Z-plasty lengthening of both the FHL and the flexor digitorum longus (FDL) tendons, which are often found to be under tension after completion of the release, thereby causing clawing of the toes and possibly impeding achievement of a satisfactory range of ankle dorsiflexion. $^{44,45}$ This Z-plasty lengthening approach results in more scarring, according to Atari, who proposed performing fractional lengthening to avoid it. ${ }^{46}$ After conducting anatomical dissection of idiopathic clubfeet of aborted foetuses, Windisch et al found these tendons to be shortened and taut only in grades III and IV clubfeet classified using the Dimeglio score. ${ }^{27}$ However, Turco considered that even if they were in tension at the time of the surgical release, they will stretch eventually if the foot is maintained in the corrected position after surgery, so he avoided lengthening these tendons. ${ }^{47}$ None of the surgically treated patients included in this study underwent lengthening of the FHL tendon. Ponseti also considered that maintaining the FHL and FDL stretched by prolonging the plaster cast underneath the plantar aspect of the toes was enough to correct their tightness. ${ }^{9}$
Our study has several limitations. The first limitation is the small number of participants. Secondly, even though the study groups were homogeneous, and all patients were active, it is impossible to estimate exactly their level of activity, which might influence the stiffness. Although it would be impossible to tell which of the ligamentous, capsular, tendinous or muscular contractures contributed most significantly to the rigidity of clubfeet, the initial severity at presentation was not recorded. The third limitation is represented by the lack of correlation of elastographic findings with histological images. For instance, in the case of surgically treated clubfeet, we think there is a possibility of observing stiffer characteristics of the subcutaneous fat secondary to resultant connective scar tissue or to abnormal tensioning of the fat tissue by the adjacent fibrous tissue. Finally, taking into consideration the fact that the success of sonoelastography can depend on the operator, only one examiner performed the examinations even though we were all present during the evaluation of patients and the elastographic sequence was examined together.

Nevertheless, we consider there might be some useful applications of sonoelastography in this particular pathology and it is worth conducting future research in some directions. While the Ponseti method constantly achieves good correction rates and has been established as the standard of treatment, the prevention of relapses can be challenging and leaves room for improvements. Ponseti considered them to be related to the retraction of the posteromedial ligaments and musculotendinous units determined by the initial persisting retracting fibrosis that produced the initial deviation. ${ }^{9}$ Sangiorgio et al estimated that relapse probability is approximately 30\%, 45\% and $52 \%$ at the ages of two, four and six years, respectively. ${ }^{48}$ After completion of the correction phase, bracing of the clubfeet in FAOs is considered extremely important, and this option is probably employed in most paediatric orthopaedics centres until children reach the age of four to five years. When applied, these devices ensure continuous stretching of the posteromedial soft tissue. Although research is ongoing to improve these devices that do not adapt perfectly to each patient's feet, noncompliance with the bracing protocol due to is a recognised problem that can affect up to $32 \%$ to $61 \%$ of patients and which increases the risk of relapse. ${ }^{49}$ Skin lesions and acceptance difficulties by the child manifesting as continuous crying or sleeping problems at nighttime are associated with poor adherence to bracing. ${ }^{50,51}$ Besides bracing, other methods 
like physical therapy, dynamic outpatient taping, and neuromuscular electrical stimulation might be useful for improving muscle balance and stretching the stiff posteromedial tissues. ${ }^{52-54}$ With respect to this idea, elastographical identification of differences in elasticity of stiff ligaments, tendons and muscles can better direct the treatment measures towards correcting the problems. The ideal patient would have a unilateral clubfoot so elasticity in the stiff structures could be compared with the normal foot but taking into consideration that correction is usually achieved before walking age and muscle-tendon elasticity is probably minimally influenced by the child's activity at this age, a set of standard quantitative elasticity measurements in the general population as a reference for bilateral clubfoot involvement could be determined.

\section{Conclusion}

In conclusion, we observed a greater degree of stiffness in tendons on the posteromedial aspect of treated clubfeet (TA, $\mathrm{TP}$ and AT), but these differences were statistically significant only at the calcaneal insertion of the Achilles tendon. Nevertheless, they might be related to the pathological anatomy of clubfeet. It might be possible that stiffness of soft tissues persists into adolescence even in case of corrected clubfeet, but to which extent its presence affects the skeletal development and relapse rates has not been elucidated. RTE and SWE might have some applicability as methods of evaluating clubfeet stiffness, but, as in other musculoskeletal applications, further studies are necessary.

\section{Funding}

This study was funded by the University of Medicine and Pharmacy Carol Davila Bucharest, which was not involved in any of the stages from study design to article submission. The authors report no conflicts of interest in this work.

\section{Disclosure}

The authors report no conflicts of interest in this work.

\section{References}

1. McConnell L, Cosma D, Vasilescu D, Morcuende J. Descriptive epidemiology of clubfoot in Romania: a clinic-based study. Eur Rev Med Pharmacol Sci. 2016;20(2):220-224.

2. Ippolito E. Update on pathologic anatomy of clubfoot. $J$ Pediatr Orthop B. 1995;4(1):17-24. doi:10.1097/01202412-199504010-00003

3. Ippolito E, Ponseti IV. Congenital clubfoot in the human fetus: a histological study. $J$ Bone Joint Surg. 1980;62-A(1):8-22 doi:10.2106/00004623-198062010-00003
4. Matsumoto F, Trudel G, Uhthoff HK, Backman DS. Mechanical effects of immobilization on the Achilles' tendon. Arch Phys Med Rehabil. 2003;84(5):662-667. doi:10.1016/s0003-9993(02)04834-7

5. Corbu A, Cosma D, Vasilescu DE, Cristea S. Congenital Talipes equinovarus: current concepts and treatment. Rev Med Chir Soc Med Nat Iasi. 2017;121(4):745-751.

6. Cosma DI, Vasilescu DE. Ponseti treatment for clubfoot in Romania: a 9-year single-centre experience. J Pediatr Orthop B. 2014;23 (6):512-516. doi:10.1097/BPB.00000000000000817

7. Corbu A, Cosma DI, Vasilescu DE, Cristea S. Posteromedial release versus Ponseti treatment of congenital idiopathic clubfoot: a long-term retrospective follow-up study into adolescence. Ther Clin Risk Manag. 2020;16:813-819. doi:10.2147/TCRM.S262199

8. Chand S, Mehtani A, Sud A, Prakash J, Sinha A, Agnihotri A. Relapse following use of Ponseti method in idiopathic clubfoot. $J$ Child Orthop. 2018;12(6):566-574. doi:10.1302/1863-2548.12.180117

9. Ponseti IV. Congenital Clubfoot. Fundamentals of Treatment. 1st ed. USA: Oxford University Press; 1996.

10. Drakonaki EE, Allen GM, Wilson DJ. Ultrasound elastography for musculoskeletal applications. $B r \quad J$ Radiol. 2012;85(1019): 1435-1445. doi:10.1259/bjr/93042867

11. Sigrist RMS, Liau J, Kaffas AE, Chammas MC, Willmann JK. Ultrasound elastography: review of techniques and clinical applications. Theranostics. 2017;7(5):1303-1329. doi:10.7150/thno.18650

12. Cosma DI, Corbu A, Nistor DV, et al. Joint hyperlaxity prevents relapses in clubfeet treated by Ponseti method-preliminary results. Int Orthop. 2018;42(10):2437-2442. doi:10.1007/s00264-018-3934-7

13. Dirrichs T, Schrading S, Gatz M, Tingart M, Kuhl CK, Quack V. Shear Wave Elastography (SWE) of asymptomatic achilles tendons: a comparison between semiprofessional athletes and the nonathletic general population. Acad Radiol. 2019;26(10):1345-1351. doi:10.10 16/j.acra.2018.12.014

14. Ponseti IV, Smoley EN. Congenital club foot: the results of treatment. J Bone Joint Surg Am. 1963;45-A(2):261-344. doi:10.2106/0000 4623-196345020-00004

15. Turco VJ. Resistant congenital club foot--one-stage posteromedial release with internal fixation. A follow-up report of a fifteen-year experience. J Bone Joint Surg Am. 1979;61(6A):805-814. doi:10.2106/00004623-197961060-00002

16. Wang JH, Guo Q, Li B. Tendon biomechanics and mechanobiology-a minireview of basic concepts and recent advancements. $J$ Hand Ther. 2012;25(2):133-141. doi:10.1016/j.jht.2011.07.004

17. Kadhum M, Lee MH, Czernuszka J, Lavy C. An analysis of the mechanical properties of the Ponseti method in clubfoot treatment. Appl Bionics Biomech. 2019;2019:4308462. doi:10.1155/2019/ 4308462

18. Uglow MG, Clarke NM. Relapse in staged surgery for congenital talipes equinovarus. J Bone Joint Surg Br. 2000;82(5):739-743. doi:10.1302/0301-620X.82B5.0820739

19. Ippolito E, Farsetti P, Caterini R, Tudisco C. Long-term comparative results in patients with congenital clubfoot treated with two different protocols. J Bone Joint Surg Am. 2003;85(7):1286-1294. doi:10. 2106/00004623-200307000-00015

20. Nahm FS. What the P values really tell us. Korean J Pain. 2017;30 (4):241-242. doi:10.3344/kjp.2017.30.4.241

21. Altman DG, Bland JM. Statistics notes: absence of evidence is not evidence of absence. BMJ. 1995;311(7003):485. doi:10.1136/bmj.31 1.7003 .485

22. Nakamura M, Ikezoe T, Takeno Y, Ichihashi N. Effects of a 4-week static stretch training program on passive stiffness of human gastrocnemius muscle-tendon unit in vivo. Eur J Appl Physiol. 2012;112 (7):2749-2755. doi:10.1007/s00421-011-2250-3

23. Zhao D, Liu J, Zhao L, Wu Z. Relapse of clubfoot after treatment with the Ponseti method and the function of the foot abduction orthosis. Clin Orthop Surg. 2014;6(3):245-252. doi:10.4055/ cios.2014.6.3.245 
24. Tardioli A, Malliaras P, Maffulli N. Immediate and short-term effects of exercise on tendon structure: biochemical, biomechanical and imaging responses. Br Med Bull. 2012;103(1):169-202. doi:10.1093/bmb/ldr052

25. Werkhausen A, Albracht K, Cronin NJ, Paulsen G, Bojsen-Møller J, Seynnes OR. Effect of training-induced changes in achilles tendon stiffness on muscle-tendon behavior during landing. Front Physiol. 2018;9:794. doi:10.3389/fphys.2018.00794

26. Ponseti IV, Campos J. The classic: observations on pathogenesis and treatment of congenital clubfoot. Clin Orthop Relat Res. 2009;467 (5):1124-1132. doi:10.1007/s11999-009-0721-1

27. Windisch G, Anderhuber F, Haldi-Brändle V, Exner GU. Anatomical study for an updated comprehension of clubfoot. Part II: ligaments, tendons and muscles. J Child Orthop. 2007;1(1):79-85. doi:10.1007/ s11832-006-0004-2

28. Gelfer Y, Dunkley M, Jackson D, et al. Evertor muscle activity as a predictor of the mid-term outcome following treatment of the idiopathic and non-idiopathic clubfoot. Bone Joint J. 2014;96-B (9):1264-1268. doi:10.1302/0301-620X.96B9.33755

29. Handelsman JE, Badalamente MA. Neuromuscular studies in clubfoot. J Pediatr Orthop. 1981;1(1):23-32. doi:10.1097/01241 398-198101010-00004

30. Feldbrin Z, Gilai AN, Ezra E, Khermosh O, Kramer U, Wientroub S. Muscle imbalance in the aetiology of idiopathic club foot. An electromyographic study. J Bone Joint Surg Br. 1995;77(4):596-601. doi:10.1302/0301-620X.77B4.7615605

31. Fried A. Recurrent congenital clubfoot; the role of the M. tibialis posterior in etiology and treatment. J Bone Joint Surg Am. 1959;41-A (2):243-252. doi:10.2106/00004623-195941020-00005

32. Bensahel H, Huguenin P, Themar-Noel C. The functional anatomy of clubfoot. J Pediatr Orthop. 1983;3(2):191-195. doi:10.1097/01241 398-198305000-00007

33. Wicart PR, Barthes X, Ghanem I, Seringe R. Clubfoot posteromedial release: advantages of tibialis anterior tendon lengthening. $J$ Pediatr Orthop. 2002;22(4):526-532. doi:10.1097/01241398-200207000-00021

34. Kuo KN, Hennigan SP, Hastings ME. Anterior tibial tendon transfer in residual dynamic clubfoot deformity. J Pediatr Orthop. 2001;21 (1):35-41. doi:10.1097/00004694-200101000-00009

35. Prado-Costa R, Rebelo J, Monteiro-Barroso J, Preto AS. Ultrasound elastography: compression elastography and shear-wave elastography in the assessment of tendon injury. Insights Imaging. 2018;9 (5):791-814. doi:10.1007/s13244-018-0642-1

36. Klauser AS, Miyamoto H, Tamegger M, et al. Achilles tendon assessed with sonoelastography: histologic agreement. Radiology. 2013;267(3):837-842. doi:10.1148/radiol.13121936

37. Ooi CC, Schneider ME, Malliaras P, Chadwick M, Connell DA. Diagnostic performance of axial-strain sonoelastography in confirming clinically diagnosed Achilles tendinopathy: comparison with B-mode ultrasound and color Doppler imaging. Ultrasound Med Biol. 2015;41(1):15-25. doi:10.1016/j.ultrasmedbio.2014.08.019

38. Aubry S, Nueffer JP, Tanter M, Becce F, Vidal C, Michel F. Viscoelasticity in Achilles tendonopathy: quantitative assessment by using real-time shear-wave elastography. Radiology. 2015;274 (3):821-829. doi:10.1148/radiol.14140434

39. James R, Kesturu G, Balian G, Chhabra AB. Tendon: biology, biomechanics, repair, growth factors, and evolving treatment options. J Hand Surg Am. 2008;33(1):102-112. doi:10.1016/j.jhsa.2007.09.007
40. Zhang LN, Wan WB, Wang YX, et al. Evaluation of elastic stiffness in healing achilles tendon after surgical repair of a tendon rupture using in vivo ultrasound shear wave elastography. Med Sci Monit. 2016;22:1186-1191. doi:10.12659/MSM.895674

41. Karatekin YS, Karaismailoglu B, Kaynak G, et al. Does elasticity of Achilles tendon change after suture applications? Evaluation of repair area by acoustic radiation force impulse elastography. J Orthop Surg Res. 2018;13(1):45. doi:10.1186/s13018-018-0751-z

42. Busilacchi A, Olivieri M, Ulisse S, et al. Real-time sonoelastography as novel follow-up method in Achilles tendon surgery. Knee Surg Sports Traumatol Arthrosc. 2016;24(7):2124-2132. doi:10.1007/ s00167-014-3484-5

43. Liu SH, Yang RS, al-Shaikh R, Lane JM. Collagen in tendon, ligament, and bone healing. A current review. Clin Orthop Relat Res. 1995;318:265-278.

44. McKay DW. New concept of and approach to clubfoot treatment: section III--evaluation and results. J Pediatr Orthop. 1983;3(2):141-148. doi:10.1097/01241398-198305000-00001 PMID: 6863519.

45. Simons GW. The complete subtalar release in clubfeet. Orthop Clin North Am. 1987;18(4):667-688. [PMID: 3313168]. doi:10.1016/ S0030-5898(20)30358-8

46. Atar D, Lehman WB, Grant AD, Strongwater AM. Fractional lengthening of the flexor tendons in clubfoot surgery. Clin Orthop. 1991;264:267-269.

47. Turco VJ. Surgical correction of the resistant club foot. One-stage posteromedial release with internal fixation: a preliminary report. J Bone Joint Surg Am. 1971;53(3):477-497. doi:10.2106/00004623197153030-00005

48. Sangiorgio SN, Ebramzadeh E, Morgan RD, Zionts LE. The timing and relevance of relapsed deformity in patients with idiopathic clubfoot. $\mathrm{J} \mathrm{Am}$ Acad Orthop Surg. 2017;25(7):536-545. doi:10.5435/jaaos-d-16-00522

49. Zionts LE, Dietz FR. Bracing following correction of idiopathic clubfoot using the Ponseti method. $J$ Am Acad Orthop Surg. 2010;18(8):486-493. doi:10.5435/00124635-201008000-00005

50. Baise M, Pohlig K. Behandlung des reversiblen dynamischen Spitzfußes mittels Unterschenkelorthesen mit ringförmiger Fussfassung. Ergebnisse bei Kindern mit infantiler Zerebralparese. Med Orth Techn. 2005;3:1-19.

51. Alves C, Escalda C, Fernandes P, Tavares D, Neves MC. Ponseti method: does age at the beginning of treatment make a difference? Clin Orthop Relat Res. 2009;467(5):1271-1277. doi:10.1007/s11999-008-0698-1

52. Singh AK, Roshan A, Ram S. Outpatient taping in the treatment of idiopathic congenital talipes equinovarus. Bone Joint J. 2013;95-B (2):271-278. doi:10.1302/0301-620X.95B2.30641

53. Nilgün B, Suat E, Engin Sİ, Fatma U, Yakut Y. Short-term results of intensive physiotherapy in clubfoot deformity treated with the Ponseti method. Pediatr Int. 2011;53(3):381-385. doi:10.1111/j.1442-200X. 2010.03243.X

54. Gelfer Y, Durham S, Daly K, Shitrit R, Smorgick Y, Ewins D. The effect of neuromuscular electrical stimulation on congenital talipes equinovarus following correction with the Ponseti method: a pilot study. J Pediatr Orthop B. 2010;19(5):390-395. doi:10.1097/BPB.0b $013 \mathrm{e} 32833$ becad 


\section{Publish your work in this journal}

The International Journal of General Medicine is an international, peer-reviewed open-access journal that focuses on general and internal medicine, pathogenesis, epidemiology, diagnosis, monitoring and treatment protocols. The journal is characterized by the rapid reporting of reviews, original research and clinical studie across all disease areas. The manuscript management system is completely online and includes a very quick and fair peer-review system, which is all easy to use. Visit http://www.dovepress.com/ testimonials.php to read real quotes from published authors.

Submit your manuscript here: https://www.dovepress.com/international-journal-of-general-medicine-journal 